\title{
Performance Assessment on the Application of Artificial Intelligence to Sustainable Supply Chain Management in the Construction Material Industry
}

\author{
Kuang-Sheng Liu ${ }^{1}$ and Ming-Hung Lin ${ }^{2, *}$ \\ 1 Department of Interior Design, Tung-Fang Design University, Kaohsiung 829003, Taiwan; \\ kliu1219@yahoo.com.tw \\ 2 Graduate Institute of Cultural and Creative Design, Tung-Fang Design University, Kaohsiung 829003, Taiwan \\ * Correspondence: mhlin@mail.tf.edu.tw
}

check for

updates

Citation: Liu, K.-S.; Lin, M.-H. Performance Assessment on the Application of Artificial Intelligence to Sustainable Supply Chain

Management in the Construction Material Industry. Sustainability 2021, 13, 12767. https://doi.org/10.3390/ su132212767

Academic Editors: Ali Bastas and Kapila Liyanage

Received: 22 September 2021

Accepted: 11 November 2021

Published: 18 November 2021

Publisher's Note: MDPI stays neutral with regard to jurisdictional claims in published maps and institutional affiliations.

Copyright: (c) 2021 by the authors. Licensee MDPI, Basel, Switzerland. This article is an open access article distributed under the terms and conditions of the Creative Commons Attribution (CC BY) license (https:// creativecommons.org/licenses/by/ $4.0 /)$.

\begin{abstract}
Along with global geopolitical complex, information network security issues and increased natural disasters, risk management should be well considered in the construction material industry to re-integrate and establish stiff and flexible supply chains in order to cope with emergencies in the future market. Taking the construction material industry in Taiwan as the research object, representative enterprises with artificial intelligence applied sustainable supply chain management are studied. With the Delphi method and data envelopment analysis, the public data of annual statistics reports of the enterprises are used for selecting the performance indicators of inputs and outputs. Empirical data analysis is also performed to provide reference for the improvement. The research results are summarized as follows. 1. Substituting various input/output index values into CCR and BCC models, the overall production efficiency and pure technical efficiency of enterprises are calculated; by dividing the two, the returns to scale of enterprises are acquired. 2. Critical factors in artificial intelligence applied sustainable supply chain management could be found out through sensitivity analysis. Using the rate of sensitivity change as the evaluation baseline, sensitive factors contain financial aspect, scale aspect, financial performance, and profit before tax. Finally, discussions are proposed according to the results, expecting to help domestic businesses in the construction material industry establish steady and flexible supply chains and present diversified procurement sources to reinforce the emergency defensive ability of the construction material industry.
\end{abstract}

Keywords: artificial intelligence; sustainable supply chain management; performance assessment; construction material industry

\section{Introduction}

To reduce costs, all activities from the acquisition of raw materials to the sale of final products or semi-finished products to their delivery to customers are realized through the establishment of the global supply chain system; meanwhile, the gradual completeness of the logistics of transport and storage as well as the related businesses makes the trend of global supply chains become obvious. The advantages of cost competitiveness and constant regional economic growth result in the diversified global supply chains in Asian markets. China has played the core role in global supply chains. The low manpower and high productivity offered for enterprises from various countries and the lower logistics and coordination costs allow the costs of the domestic production or manufacturing to be far lower than those in other countries. It also results in many enterprises moving the manufacturing to developing countries, similar to Mainland China, in Asia to increase single-country or region supply chains. The early construction industry in Taiwan stressed standard information management but ignored the information integration of suppliers and business owners and did not completely enter the supply chain system to face the fierce environmental competition. The core of supply chain management used to focus 
on efficiency, cost, and quality, with customer value maximization as the priority, but ignored the risk control of supply chains. Along with global geopolitical and complex information network security issues and increasing natural disasters, business owners have to think improving risk management and re-integrating and establishing stiff and flexible supply chains in order to cope with emergency in the future market. Major emergencies in global supply chains, including natural disasters, man-made destruction, or financial crises, might result in the emergent disruption of the supply chain network, and the most serious situation would result in out of production or factory closure of enterprises. In the face of emergent disruption risks in supply chains, adopting effective contingency strategies to slow down negative impacts caused by supply chain disruption risks and enhancing the resilience of supply chains and enterprises to face crises become important issues for enterprises. The analysis report of Gartner, a famous management consulting firm, indicated that emerging technologies deeply affected supply chain management; for instance, emerging technologies of artificial intelligence, blockchain, and the Internet of Things deeply benefitted relationship management and information flow management in supply chain management, as well as the connection between corporate supply chain and the entire industry and cross-industry. Supply chain management would present better intelligence and automation. Research revealed positive effects of digital transformation on the integration of the supply chain, positive relations between supply chain integration and supply chain performance, as well as positive relations between digital transformation and supply chain performance [1]. The digitalization of the supply chain became the mainstream to establish intelligent supply chain management systems. The introduction of emerging technologies, e.g., blockchain and the Internet of Things, into intelligent supply chains and the combination with the decision-making and analysis process of original supply chain systems could enhance the tracing and prediction functions of supply chain management, flexibly and rapidly respond to customer needs, enhancing the interconnection and coordination among supply chain stakeholders, and promoting risk management ability [2].

The major difficulty encountered by many enterprises is "challenges in the economic environment". From the China-United States trade war in 2019 to the COVID-19 epidemic shock in 2020, it reveals that challenges in the economic environment are the key in the survival and sustainable development of enterprises. In this case, business leaders should clearly understand the risks in the supply chain operation and lead employees to cope with crises; meanwhile, supply chain evaluation and risk management should be emphasized. In terms of the internal governance of a company, enterprises should deliberately plan countermeasures to slow down the epidemic shock to the entire operation process and the supply chains and positively reinforce the stiffness of supply chains through complete digital automation process to change "efficiency centered" supply chains in the past into "stiffness priority" and make efforts on the recombination of supply chains. The regionalization, localization, and decentralization of supply chains become the essential trend. According to the research of the OECD, it was mentioned in the World Circular Economy Forum 2018 and the 11th Working Party on Resource Productivity and Waste (OECD) that driven by the factors of the continuous growth of population and the constantly developing economy, it was predicted with the ENV-Linkages model that the global economy would grow by four times in 2060 and the amount of raw material usage would double; due to the large application of raw materials in the world, the usage would see multiple growth in the future decades (from 79 billion tons in 2011 to 16.7 billion tons in 2060), where raw materials for construction would be needed the most. It is also discovered by enterprises in various countries that it is necessary to rely on stiff supply chains for their survival. Coping with the recombination of global supply chains, steady and flexible supply chains are extremely important for the survival of enterprises. Diversified procurement sources could reinforce the emergency defensive ability of enterprises. As a result, making good supply chain management strategies to cope with supply chain disruption risks is essential in the changeable environment. The 
reorganization of supply chains and the emphasis on sustainable supply chain management are urgent issues for enterprises. The governance and sustainable development of supply chains to slow down the impacts on industries becomes the primary issue for governments and enterprises in various countries. The performance assessment on the application of artificial intelligence to sustainable supply chain management is therefore discussed in this study, expecting to help the construction material industry in Taiwan establish steady and flexible supply chains and possess diversified procurement sources to reinforce its emergency defensive ability.

\section{Literature Review}

\subsection{Artificial Intelligence}

Before the discussion over artificial intelligence, the meaning of "intelligence" should be understood. The term intelligence was originated from Latin "legeve", meaning to collect and combine affairs, engage in selection, and further understand and know affairs [3]. Computers being able to know, understand, perceive, learn, select, and judge affairs as humans would is called artificial intelligence. Ivanov et al. [4] defined artificial intelligence, in simplicity, as using science to have computers present intelligent characteristics. Agarwal and Goel [5] defined artificial intelligence as having computers be able to do things which were currently done better by humans. Brettel et al. [6] regarded artificial intelligence as to constantly give human intelligence to machines for being able to simulate or substitute human intelligence. In this case, artificial intelligence was to mechanize or materialize human intelligence and further extend the effect intensity and sphere of action of human intelligence for computers being able to think and judge as human brains and present learning and problem-solving abilities.

From the overall research on artificial intelligence, Lee et al. [7] pointed out the broad application of artificial intelligence, including Expert System, Natural Language Processing, Robotics, Perception Problem, Automatic Programming, Machine Learning, Problem Solving, Game playing, machine translation, voice recognition, and Intelligent Agent.

\subsection{Smart Supply Chain Management}

Hong et al. [8] mentioned that enterprises had to coordinate suppliers through supply chain management to acquire competitive advantages in the dynamic and changeable supplier environment so that suppliers became a part of the business strategies and enterprises and suppliers, in regard to resource integration, capability matching, and operating profit, collaboratively and positively responded to clients' needs. In this case, the cooperation between enterprises and the suppliers could realize high-level flexibility and performance exceeding a single enterprise. For this reason, the cooperation with suppliers to build the supply chain system is an important factor in enterprises acquiring competitive advantages. Enrique and Juan [9] indicated that enterprises and suppliers, in the process of collaboratively building the supply chain system, should be consistent in integrating and sharing the resources and capabilities in the cooperation programs, e.g., logistics capability and resource coordination capability, to develop a synergistic effect when competing with companies beyond the supply chain system. The faster response of supply chains could be realized by the cooperation between enterprises and suppliers. Wang [10] stated that the rapid development of the IoT (Internet of Things) had enterprises gradually concerned about the digital transformation with the integration of supply chain systems and the IoT. The IoT could provide advanced technologies to facilitate software application and realize the massive connection among hardware. The IoT was broadly applied to logistics tracking, product information identity, and pricing concerned in supply chain systems and was further integrated with ICT and cloud computing. The IoT could be comprehensively integrated into the daily management of enterprises. The introduction of the IoT gradually strengthened the rapid response capability, integration capability, and coordination capability in supply chain systems to become smart supply chain systems. 


\subsection{Application of Artificial Intelligence to Supply Chain}

Wang et al. [11] mentioned that the formation of an artificial intelligence supply chain relied on the construction of management capability systems. Such capability contained six factors.

\subsubsection{Understanding Customers' True Value Appeal}

Ardito et al. [12] indicated that understanding the true value appeal of supply chain customers (referring to the general idea covering ultimate consumers or purchasers and all main bodies cooperating with enterprises) was the premise of a pull supply chain, which required the real insight of customers' inner economic and emotional appeal, rather than the external product and business needs.

\subsubsection{Supply Chain Whole Process Visualization}

Chase et al. [13] defined supply chain whole process visualization management as participants in the supply chain being able to instantly respond to the whole process of supply chain and domestic and foreign market state and operation as well as to track logistics and trading state and activity to realize the instant inspection and control in the supply chain operation process. Such a goal could hardly be realized under a traditional industrial supply chain because of more complicated supply chain participants, inconsistent information systems, more manual intervention, and a lack of production and manufacturing effectiveness and high efficiency. Suppliers could not guarantee the quality to result in excessive products being recalled [14]. For this reason, the realization of supply chain whole process visualization becomes the key in artificial intelligence supply chain. The formation of such ability requires technologies of the Internet, the Internet of Things, and RFID to build the really standardized, normalized, and visualized supply chain network.

\subsubsection{Building Modularized Supply Chain Operation Structure}

Dong and Dong [15] stated that an artificial intelligence supply chain pursued the supply chain system fully responding to true value appeal with instant and effective design, construction, and operation. The application of modularized supply chain integration could rapidly apply the ability of a main body or institution, including individual and external third parties, to build the unique supply chain competitiveness. Without damaging the original system to realize the rapidly custom-made supply chain service function, it presents good intelligence response and processing ability. In other words, the flexible organization ability of an artificial intelligence supply chain would be stronger.

\subsubsection{Real-Time Supply Chain Planning and Execution of Connection System}

Alkayal et al. [16] explained that the connection of supply chain planning and execution of the system could be realized at the data and process levels. The effective supply chain planning and execution of the supply chain operation relied on the synchronicity of data and information; correspondingly, the organization and management process should be synchronized. For either planning or execution, the required data and information covered historical events as well as those that are happening and are going to happen [17]. In this case, the idea of synchronization was to instantly acquire the past, immediate, and possible information and data during supply chain planning as well as contain the planning of the supply chain. Meanwhile, the instant resource allocation and ability, according to the actual conditions and the next execution activity during the supply chain execution process, allowed the stable and effective execution of the supply chain.

\subsubsection{Sound Reports and Performance Management as well as Good Supply Chain Early Warning}

Kang and Moon [18] explained it as being able to apply supply chain analysis tools to compare expectation and actual effect, realize statistical process control, and prevent supply chain disruption or other risks caused by the operation of supply chain exceed- 
ing the expected range. The core of the artificial intelligence supply chain management was to realize highly intellectual supply chain application and effective and clear performance measurement and management, build the early warning system through various links, main bodies, and levels of the supply chain, as well as guarantee the continuous processing, stable quality, and controllable costs of supply chain activity. Hofmann and Osterwalder [19] indicated that the application of new media to acquire customer feedback, reduce operation costs, and quickly adapt to customer needs was the mostly concerned issues of enterprises in the global supply chain survey made by Kevin O'Marah, from SCM World. Apparently, the comprehensive management and early warning to realize link and process performance when fulfilling high value-added supply chain operations were the key to really confirm the artificial intelligence supply chain.

\subsubsection{Building Operation Sensitized Supply Chain}

Chai et al. [20] pointed out supply chain sensitization as the combination of supply chain artificial intelligence sensitization (i.e., rapid response) and high-efficient lean (i.e., best total cost). The idea of sensitization was first proposed by Ben Naylor; lean and sensitive used to be regarded as two states in supply chain operation, which were independent and separately appearing effects on four major elements of supply chain value (i.e., efficiency, cost, service, and speed). The lower product business diversity resulted in smaller market change than a high-efficiency and low-cost lean supply chain could establish [21]. On the contrary, larger variety differences would appear to have stronger market volatility than the lean supply chain pursuing speed and service could establish. Ma Gloria [22] considered that lean and sensitive states could be simultaneously realized in the same supply chain system, without mutual exclusion; the key was to design and arrange decoupling points according to the market conditions and industrial operation characteristics, i.e., the possession of inventory buffer points. Florian and Abubaker [23] stated that an artificial intelligence supply chain was established by applying modern technologies of the Internet, the Internet of Things, and cloud computing to realize the transfer of decoupling points. The upstream decoupling point of supply chain operation relied on prediction, while it followed the information and data operations which actually happened and were going to happen in the downstream. Before the emergence of emerging technology, the smooth and effective supply chain operation, to a large extent, depended on high-precision prediction. Under the situation of production and delivery by stocks, even though the stability of upstream production operation costs was controllable, high inventory carrying costs would appear in downstream once errors were predicted or markets were changed, and the service standard would be affected [24]. Under build-to-order and assembly, although the customer service ability of supply chain was enhanced, the reducing predictive component resulting in a decrease in downstream inventory carrying would cause production operation pressure in the upstream decoupling point, e.g., insufficient capacity, short time, and resource shortage. For this reason, the past theory and practice regarded lean and sensitive being mutually exclusive [25]. Rajaguru and Matanda [26] mentioned that an artificial intelligence supply chain required an enterprise fully applying technologies of the Internet, the Internet of Things, and cloud computing to have all supply chain links, particularly the behavioral changes of end users, be instantly responded to, mastered, and analyzed, decoupling points able to move upstream along with the supply chain, and realize orderly, stable, and highly effective upstream production and operation when guaranteeing the service quality and downstream low stock costs.

\subsection{Application of Artificial Intelligence to Supply Chain in Construction Materials Industry}

Through deep analyses of the construction materials industry, Lasi et al. [27] provided top design and planning for business owners from the whole process optimization design of material procurement, logistics and transportation, production and processing, product sales, financial settlement, and financial risk. Focusing on the steel construction smart manufacturing cloud platform and trusted to ERP information platform, logistics 
platform, e-commerce platform, and financial platform, a comprehensive construction material production and distribution platform system with the integration of production and processing, warehouses, and logistics and transportation was created. Wang et al. [28] indicated that the construction materials industry realized the coordination of the whole supply chain network by providing the smart manufacturing cloud platform with intelligent full type of business closed loop and building the complete cloud manufacturing information platform with the integration of information systems of e-commerce, the BIM cloud platform, PLM, MES, PCS, IFM, 3DIFCS, WMS, ERP, and TMS. The created smart manufacturing cloud platform helped smart manufacturing companies largely enhance the efficiency on process nodes of contract performance, order scheduling, production, warehouse storage, production and distribution, and settlement. The construction materials industry smart manufacturing cloud platform, according to the actual production requirements for the smart manufacturing of different production workshops and various types of products, executed strategic personalized configuration through strong rule engines and realized the production support for products with various characteristics, from customers placing orders to custom-made production, accurate distribution, the guarantee of fine production, storage, contract signing, settlement management, saved labor costs, production costs, and logistics costs, as well as realized paperless workshops and storehouse operations and unmanned operation, to be the benchmark of 4M1E (man, machine, material, method, and environment) transparent management. Yin and Kaynak [29] stated that the construction materials industry moved upwardly through e-commerce platforms for customers offline/online signing electronic contracts, with one-stop shopping, and moved downwardly through TMS logistics platforms linking with shipping information for clear contract progress. The connection with electronic signatures at the end presented whole paperless operation of the process and a strict, transparent, and closed-loop information flow, and the connection with risk control, finance, and financial systems was realized the integration of capital flow, information flow, and logistics information. All ERP processes were standardized and transparent, and the contract fund return cycle was shortened from the original 1-3 months to 1 week, largely reducing the fund pressure of suppliers, platforms, and common carriers to make profits.

\subsection{Sustainable Supply Chain Management}

$\mathrm{Hu}$ et al. [30] defined sustainable supply chain management as the process of the strategic economic achievement of enterprises, the environmental and social goals achieved by the coordination and cooperation among enterprises, and the enhancement of financial growth or business performance. Fornell and Larcker [31] defined sustainable supply chain management as being responsible for information, capital flow, the management of materials and cooperative supply chains among different companies, and, meanwhile, acquiring the goal of sustainable development from stakeholders and consumer needs. Sharma et al. [32] explained the meaning of sustainable supply chain management as manufacturers cooperating with the supply chain members and co-managing the internal procedures of enterprises to realize the goal of sustainable development. Bandar [33] emphasized that sustainable supply chain management increased sustainability in traditional SCM process and considered the financial, environmental, and social effects of company activities. Apparently, sustainable supply chain management was regarded as the important process of a company organizing corporate social responsibility. It was further indicated that sustainable supply chain management was the integration of traditional supply chain and green practice. Mensah and Mensah [34] indicated in the research that sustainable supply chain management stood for the strategic decisions made by enterprises in the business environmental competition, which stressed on the business practice to enhance sustainable development. In addition to enhancing the supply chain management capability, sustainable supply chain management was absolutely the key in the sustainable development of enterprises to acquire competitive advantages. Traditional supply chain management focused on quality, price, and service and simply stressed on acquiring better 
service with more efficient methods. Now, more enterprises extend the promise fulfillment of corporate social responsibility from subsidiaries to suppliers. It is not simply because the practice of such promise could avoid possible social and environmental risks and supervision difficult in supply chain, but sustainable supply chain management could result in long-term benefits for enterprises. Actually, a successful sustainable supply chain management mechanism could make excellent corporate governance and result in better performance for both enterprises and society [35].

\subsection{Sustainable Performance}

Liu et al. [36] considered that sustainable performance consisted of economy, environment, and society, as the triple bottom line. Sustainable performance stood for the persistent competitive advantage of an enterprise acquiring economic returns by considering the effects of natural environment and human society and not sacrificing stakeholders' needs. Githiri et al. [37] revealed that enterprises' positivity to sustainability could generate the corporate competitiveness, economic benefits, and better social responsibility for the public. Akhigbe and Olokoyo [38] regarded sustainable development performance so as to measure the process of an organization integrating environmental, societal, and economic prosperity into the operation to realize the long-term goals. Sustainable performance was to expand financial performance to the triple bottom line, including the environmental and social performance of the company. In other words, sustainable performance was the efficacy and efficiency of enterprises promoting sustainable supply chain management. Regarding the research on sustainable performance, environmental, social, and economic performance was mostly assessed for sustainable performance, after Tseng et al. [39] included the triple bottom line in their performance assessment. Enterprises and supply chains used to use short-term economic performance as the sole standard of the resource application's efficacy. When environmental resources on the Earth became scarce, supply chains discovered the worsening problem in resource shortage, started to pay attention to the concern about the environment, the area, and society, and included long-term environmental and social performance in the supply chain partner standards to have enterprises concern themselves about and stress sustainable performance issues, with strong power. Summing up the above literature review of sustainable performance, sustainable performance stands for the long-term competitive advantage in the acquired economic returns by enterprises considering its effects on the natural environment and human society and not sacrificing the needs of stakeholders as well as the realization of the long-term goals. Choi et al. [40] discussed the advantage and effect of the application of artificial intelligence to financial performance in the past research, where the application of artificial intelligence presented positive correlations with financial performance. It was also mentioned that artificial intelligence was used as data storage technology and was related to financial performance. Based on the research of Ivanov, Webster, and Berezina [41], tourism, travel, and hotel companies utilized robots and robotic artificial intelligence and service automation (RAISA) for service information/check-in/check-out information kiosks in the practice of distributed robots, robot concierges, conveyor belt restaurants, and self-service with artificial intelligence. The study first discussed the positive effect of the application of artificial intelligence to the performance of collaboration team and the real financial performance of enterprises. Patel et al. [42] studied artificial intelligence and the positive outcome on the biomedicine performance in Europe and mentioned that artificial intelligence adopted positive participation in the decision-making process in health care systems to reduce handling time, and the reduction in handling time resulted in better financial performance.

\section{Research Indicator and Object}

\subsection{Establishment of Research Indicator}

From the above indicators from researchers assessing the performance of the application of artificial intelligence to sustainable supply chain management, the Delphi method is utilized in this study for making indicators of artificial intelligence applied sustain- 
able supply chain management. The Delphi method, also named expert judgment, as a group decision-making method with qualitative and quantitative characteristics, is interdisciplinary and future-oriented and could reduce differences in expert opinions through anonymous questionnaire survey with several runs of repeated voting and feedback for a commonly accepted answer.

The so-called "experts", according to the suggestions in the literature [43], should present the conditions of (1) presenting interests in collaboratively participating in the survey with the Delphi method, (2) presenting rich information for sharing, (3) showing approved knowledge and technology in special fields, (4) presenting expertise on the surveyed subject, including practical experience and theoretical research, and (5) agreeing with the research results covering the possessed special information. Mishra and Chatterjee [44] indicated that experts had to present knowledge standards, reliability, and accuracy and show deeper knowledge than laymen so that experts' judgment could better approach the truth than ordinary people. The value of the Delphi method is built based on above such answers. To combine the selection of input/output factors with expert opinions, reduce input costs, and avoid fuzziness in the survey process, a Modified Delphi Method is utilized in this study for selecting input/output factors. Based on special considerations of part of the research, the brainstorming open-ended questionnaire is omitted. After referring to a large amount of the relevant literature, the structured questionnaire is directly developed for the first-run questionnaire survey. It is the Modified Delphi Method, which directly uses a structured questionnaire for the first-run survey to save lots of time; in addition, the structured questionnaire could have the experts participating in the research concentrate on the research topic, without making guesses in the open-ended questionnaire. A total of 50 copies of the questionnaire were distributed, and 35 valid copies were retrieved, with a retrieval rate of $70 \%$. Researchers indicate that public opinions with more than five participants could be the analysis reference. The surveyed experts in this study cover industry experts, officials, and academics and show frequent interaction with the construction material industry, so they should present certain representativeness.

\subsection{Establishment of Evaluation Indicator}

The evaluation indicators in this study are established according to the Delphi method and past literature. The variables are defined as below:

(1) Inputs:

Financial aspect: including capitals of artificial intelligence applied sustainable supply chain management system construction cost and personnel cost (unit: thousand NT dollars);

Scale aspect: containing the number of firms investing in the artificial intelligence applied sustainable supply chain management system (unit: number of firms).

(2) Outputs:

Financial performance: business performance of enterprises (unit: thousand NT dollars);

Profit before tax: profit before tax $=$ operating profit + non-operating earnings (losses) (unit: thousand NT dollars). It shows whether a company makes money before paying taxes.

\subsection{Research Method and Object}

In terms of the research object, enterprises in the construction material industry in Taiwan representing artificial intelligence applied sustainable supply chain management are selected. The Delphi method and data envelopment analysis are utilized in this study. According to the public data of enterprises, the annual statistics reports are regarded as the data for selecting the input/output performance indicators, and empirical data analysis is used to provide reference for improvement. Data envelopment analysis can deal with problems with multiple inputs and outputs, but the handled numbers are not unlimited. When a decision-making unit shows an output-input ratio higher than the other DMUs, the DMU is relatively efficient. Accordingly, the increase in an input/output would have to reduce the discriminating power such as the price. According to the empirical rules, the number of decision-making units should be at least twice of the sum of the numbers of 
inputs and outputs. Aiming at such research objects, total of 12 DMUs are evaluated in this study.

\subsection{Efficiency Evaluation Analysis}

Data envelopment analysis (DEA) is used as the tool for evaluating efficiency in this study. Different from traditional regression analysis, which merely searches for the average path from a series of data, DEA envelops the data of various samples and attempts to find out their relationship and presents the advantages necessary for a good efficiency evaluation model. The method applies linear planning, considers factors in the measurement of performance among various DMUs, and compares the performance of units with similar characteristics.

Early theory of economics mostly calculated the possible curve of production with default production function to evaluate the productivity of an organization. Farrell, in 1957, replaced "default production function" with "non-default production function", through mathematical programming, to calculate the efficiency frontier curve and evaluate the technical and price efficiency of evaluated units. Nevertheless, the evaluation with Farrell's model was restricted to a single output whose use was limited. According to Farrell's efficiency evaluation concept, Charnes, Cooper, and Rhodes (CCR) [44], proposed the multiple evaluation criteria environment with various inputs and outputs under constant returns and named it data envelopment analysis (DEA).

The CCR model is a fractional linear programming problem proposed by Charnes, Cooper, and Rhodes [45] for evaluating the relative efficiency of an organization. The feasible region formed by the programming was composed of infinite non-negative weighted numerical solutions. For the k-th DMU, DEA could select a weighted numerical solution to have the k-th DMU reach the maximal efficiency (but not higher than 1) (objective function); in addition, the weighted numerical solution, when being substituted into other DMUs, would not have the efficiency of other DMUs be higher than 1 (constrains); therefore, the weights were not subjectively decided.

The BCC model was proposed by Banker, Charnes, and Cooper [46] by expanding the viewpoint of efficiency and application in the CCR model. Since the CCR model could not interpret whether the inefficiency of DMUs was caused by technical inefficiency or scale inefficiency and the BCC model assumed variable returns to scale, i.e., increasing inputs without relatively increasing a part of outputs, the model could calculate pure technical efficiency, scale efficiency, and return to scale of DMUs.

\section{Empirical Analysis of Artificial Intelligence Applied Sustainable Supply Chain Management Performance Assessment}

\subsection{Analysis of Performance Assessment}

After substituting various input/output indicators into the CCR and BCC models, the overall production efficiency and pure technical efficiency of enterprises could be calculated, and the returns to scale of enterprises could be acquired by dividing the two. The CCR and BCC models are two common models in DEA; the CCR model can calculate the total efficiency and the BCC model can calculate the pure technical efficiency and scale efficiency. The overall production efficiency, pure technical efficiency, and scale efficiency are organized in Table 1.

From Table 1, Sun Yad, with the overall production efficiency $=1$, is relatively the most efficient enterprise, while the rest of the enterprises show low overall production efficiency; especially, ChainQui, with the lowest overall efficiency, is relatively the most inefficient enterprise. That is, 11 DMUs are relatively inefficient enterprises, except for $1 \mathrm{DMU}$ with the overall production efficiency $=1$. The reason for the inefficiency might be the inputs not being effectively applied or not reaching the optimal production scale. It requires further analyses. 
Table 1. Relative efficiency of enterprises.

\begin{tabular}{cccc}
\hline DMU & Overall Efficiency & Technical Efficiency & Scale Efficiency \\
\hline Sun Yad & 1.00 & 1.00 & 1.00 \\
Hua Yu Lien & 0.98 & 0.98 & 0.97 \\
SanDi & 0.94 & 0.94 & 0.94 \\
Advancetek & 0.83 & 0.82 & 0.83 \\
Ta Jiang & 0.78 & 0.79 & 0.78 \\
I-Hwa & 0.90 & 0.91 & 0.89 \\
Better Life Group & 0.88 & 0.88 & 0.87 \\
Run Long & 0.85 & 0.86 & 0.84 \\
Cathay Real Estate Development & 0.81 & 0.81 & 0.80 \\
Pacific Construction & 0.76 & 0.77 & 0.75 \\
ChainQui & 0.70 & 0.70 & 0.70 \\
Prince Housing and Development & 0.86 & 0.85 & 0.87 \\
\hline
\end{tabular}

\subsection{Sensitivity Analysis}

Since there is no default production function in the efficiency measurement with DEA, DEA is sensitive to the changes in the number of DMUs or inputs/outputs. To avoid bias caused by manual operation, sensitivity analysis, with following two methods, can be performed:

(1) Execute the evaluation result again after reducing or increasing 1 DMU;

(2) Then, execute the evaluation result again after reducing or increasing an input/output or consolidating factor.

The second method is applied in this study. Using the construction material industry as the data, the evaluation result is executed again after reducing an input or output and compares the result with the original result to analyze the effects of inputs/outputs on the efficiency. The Spearman's rank correlation analysis test is further conducted to understand the correlation. A higher correlation coefficient reveals the greater reliability of the acquired relative efficiency and the selected inputs/outputs and the lower possibility of bias.

The analysis result, Table 2, shows that loan in outputs is the key factor. Any types of efficiency would appear to have the largest decrease when the loan is removed. Capital charges in inputs are the key factors in inputs in that any type of efficiency would also appear to have the largest decrease when capital charges are removed.

Table 2. Sensitivity analysis.

\begin{tabular}{cccccc}
\hline & \multicolumn{2}{c}{ Input Reduce Item } & \multicolumn{2}{c}{ Output Reduce Item } & \multirow{2}{*}{ Raw Value } \\
\cline { 2 - 5 } & Financial Aspect & Scale Aspect & Financial Performance & Profit before Tax & \\
\hline Overall mean & 0.80 & 0.78 & 0.71 & 0.70 & 0.86 \\
\hline
\end{tabular}

The Spearman's rank correlation analysis test results, Table 3, reveal highly positive correlations between the relative efficiency calculated by reducing any output/input and the original efficiency, with significance. The selection of inputs/outputs in this study is therefore appropriate, and the relative efficiency analysis result should present favorable reference value.

Table 3. Spearman's correlation analysis of sensitivity analysis and original efficiency.

\begin{tabular}{ccccc}
\hline & \multicolumn{2}{c}{ Input Reduce Item } & \multicolumn{2}{c}{ Output Reduce Item } \\
\cline { 2 - 5 } & Financial Aspect & Scale Aspect & Financial Performance & Profit before Tax \\
\hline Overall efficiency & $0.928^{* * *}$ & $0.823^{* * *}$ & $0.944^{* * *}$ & $0.858^{* * *}$ \\
Technical efficiency & $0.914^{* * *}$ & $0.757^{* * *}$ & $0.915^{* * *}$ & $0.852^{* * *}$ \\
Scale efficiency & $0.940^{* * *}$ & $0.874^{* * *}$ & $0.869^{* * *}$ & $0.820^{* * *}$ \\
\hline
\end{tabular}

Note: ${ }^{* *}$ for $p<0.001$. Data source: Self-organized in this study. 


\section{Discussion}

\subsection{Main Contribution}

First, the construction materials industry should stress digital transformation. In the establishment of artificial intelligence applied sustainable supply chain management, data are the most important factor. Second, in the cooperation process with major suppliers, suppliers should be regarded as important stakeholders in the artificial intelligence applied sustainable supply chain management to coordinate suppliers' interest expectation and generate synergistic effect. Finally, a big company should bear the responsibility for the promotion of industrial progress and develop the influence on the ecosystem. Artificial intelligence applied sustainable supply chain management is affected by external stakeholders to result in major changes in the sustainability measures and requirements for the artificial intelligence in the supply chain and further affect the sustainable development implementation and strategies in the construction materials industry. The sustainable development in the construction materials industry requires the full and clear understanding of external stakeholders' cognition and awareness, the prediction of the future market and environment changes, as well as rapid responses to the change in the external environment in order to reduce the negative effects on the construction materials industry and supply chains. When practicing artificial intelligence and sustainable development strategies, the construction materials industry will encounter many difficulties and problems. The construction materials industry should internally keep positive attitudes towards artificial intelligence and sustainable development to effectively enhance the sustainable performance. External supply chains are regulated and requested by governmental regulations and policies. When the public and non-profit organizations perceive serious destruction of the Earth, they would propose requirements for the artificial intelligence and sustainability strategies and measures of the construction materials industry and start to search for environment-friendly construction materials and supply chains to express the support of artificial intelligence and sustainability. Downstream partners of supply chains would be requested and influenced externally and propose requirements for artificial intelligence and sustainability internally. The construction materials industry, being affected by external stakeholders and being requested and regulated by internal supply chains, would improve the internal process and products and enhance the artificial intelligence and environmental and society-friendly measures and concerns. For implementing measures related to artificial intelligence and sustainable development, a large amount of costs would be paid, which, in the short term, might damage the economic performance but could enhance the image and product competitiveness, after long-term implementation, to further promote the economic performance. When making sustainability strategies, the construction materials industry is mostly restricted to the requirements and standards of government decrees, and merely a few corresponding strategies were made with enterprises' autonomy. Government policies require multiple considerations and discussions in order to be applicable to various industries. It results in domestic construction materials industries not being able to gear to international standards due to slow decree revision, while some methods and strategies have been preceded internationally. To enhance the international competitiveness, the construction materials industry has to enhance the sustainability standards of the enterprises and make more diversified sustainability strategies. Many businesses in the construction materials industry simply follow the standards required by government decrees. Research analyses reveal that the implementation of sustainability strategies allows the construction materials industry to receive more benefits than the paid resources, which are not simply the economic benefits but good image recognized by the government and the public, as well as the promotion of competitiveness in the industry. The research also discovers that including suppliers in the artificial intelligence supply chain building process could find out the differences between supplier management and artificial intelligence supply chain management (Table 4). 
Table 4. Difference between supplier management and artificial intelligence supply chain management.

\begin{tabular}{ll}
\hline Supplier Management & Artificial Intelligence Supply Chain Management \\
\hline Aiming at single supplier & Aiming at several suppliers in the supply chain \\
\hline Mid-term commitment & Long-term commitment \\
\hline Medium communication & High communication \\
\hline Middle manager & Top manager \\
\hline Pure trading, slightly involving in strategies & Strategies applied to all parts, allies \\
\hline Not necessarily building criteria for suppliers & Stressing on process management \\
\hline Concentrating on suppliers' capability & Paying attention to the integration of entire supply chain system \\
\hline
\end{tabular}

\subsection{Theory and Contribution}

Although enterprises would purchase different core products through distinct supply chain parts, supplier composition, and structure of supply chain management system, the contents concerned by major stakeholders are generally the same. Core firms and major suppliers would pay attention to the timeliness of the supply chain, the problem response speed, and agility and flexibility. Some researchers proposed that enterprises, in the dynamic and changeable supplier environment, had to coordinate suppliers through supply chain management to have suppliers become a part of the operation strategies in order to acquire the competitive advantages. In terms of resource integration, capability match, and operation profit, enterprises and suppliers had to positively respond to customer needs. In this case, enterprises cooperating with the suppliers could realize higher flexibility and performance beyond single enterprise [47]. Accordingly, cooperating with suppliers to build the supply chain system was a key factor in enterprises acquiring competitive advantages. In the process to collaboratively build the supply chain system with suppliers, enterprises and suppliers had to coordinate, integrate, and share the resources and capabilities in the cooperation program in the supply chain, such as logistics capability and resource coordination ability, to develop the synergy effect when competing with companies beyond the supply chain system [48]. The fast response of the supply chain could be realized by the cooperation of enterprises and suppliers.

\subsection{Research Limitation}

Enterprises in the construction materials industry in Taiwan are set for this study. According to the industrial classification of the government, there are various categories; however, merely 12 enterprises in the construction materials industry are studied. It does not show representativeness and could not exactly express the difficulties and sources of the effects of enterprises in the construction materials industry in Taiwan encountering in the supply chain sustainability. Reducing the set industry would be able to provide more accurate suggestions and assistance for enterprises in the industry.

\section{Conclusions}

From the efficiency acquired from DEA and the information of variables, one DMU, about $8 \%$ of all DMUs, shows strong-form performance efficiency on the artificial intelligence applied sustainable supply chain management (efficiency $=1$ ), revealing the better efficiency in the execution of artificial intelligence applied sustainable supply chain management. Three DMUs, about $25 \%$ of all DMUs, show the efficiency of artificial intelligence applied sustainable supply chain management in 0.9-1, as marginal inefficiency, revealing the efficiency could be more easily enhanced. Eight DMUs, about $67 \%$ of all DMUs, have an efficiency of the artificial intelligence applied sustainable supply chain management performance lower than 0.9 , an obvious inefficiency, where ChainQui shows the lowest efficiency. 
The research results, similar to the research of Sanders and Swink [49], reveal that the full coordination and cooperation of an enterprise with the suppliers in the processes of supply chain data collection, data processing, management integration, and test monitoring would form the data point of suppliers' data and the overall supply chain data point with the combination of the supply chain big data and management process of the enterprise to timely track problems and real-time respond to supply chain as well as propose finer data analyses, early warning, instant notification, and system records for coordinating suppliers' synchronous processing and providing real-time responses to customers. As mentioned by Scholz et al. [50], a company in the smart supply chain management system could realize the artificial intelligence supply chain management based on the emerging technologies of the Internet of Things and cloud computing in the entire supply chain management system by forming the intelligent supply chain big data management system with the major suppliers, co-participated by all stakeholders, and realizing finer and faster track and management.

In consideration of the traditional supply chain management model not being able to cope with the changeable information time, the construction materials industry has to thoroughly digitalize the supply chain process by controlling the risk degree between upstream suppliers and downstream clients through data analysis and setting risk alert to instantaneously prevent any parts of the supply chains from supply chain disruption risks. Furthermore, corporate culture is also an important factor in the stiffness and flexibility of supply chains. Some businesses in the construction materials industry, when encountering a major emergency, could rapidly rebound to the original state and even become stronger through reflection. It is the direct realization of stiffness and flexibility of supply chains. To meet the time for global supply chain reorganization, creating stiff supply chains with international business partners is a key issue for current construction material industry.

\section{Suggestion for Future Research}

Due to the limitations of information collection, finances, and materials, no more samples are collected for this study. It is suggested that the successive researchers could discuss with longer period or cooperate with the government to provide more complete suggestions for the construction materials industry.

1. Longitudinal study

It is considered in this study that the construction materials industry, in the practice of an artificial intelligence supply chain, could deeply discuss a single case, with longitudinal study to acquire complete analysis and understanding. The long-period analysis from the beginning of the practice of an artificial intelligence sustainable supply chain to the benefits and effort after the implementation of an artificial intelligence sustainable supply chain could better present the difficulty encountered by the construction materials industry in the actual operation. The successive researchers therefore could observe the operation of construction materials industry practicing artificial intelligence sustainable supply chain through longitudinal study.

2. Skilled interview skills

It is considered in this study that qualitative research could be adopted, with the data source from interview contents. The accuracy of interview content and the rapid discovery of points in interviewees' answers to instantly ask for deeper details are extremely important for effectively acquiring points in the successive analysis. As a result, a researcher should be familiar with interview skills and conduct rehearsals in qualitative research.

Author Contributions: Conceptualization, K.-S.L.; methodology, K.-S.L.; software, K.-S.L.; validation, K.-S.L.; formal analysis, K.-S.L.; investigation, M.-H.L.; resources, K.-S.L. and M.-H.L.; data curation, K.-S.L. and M.-H.L.; writing-original draft preparation, K.-S.L. and M.-H.L.; writing-review and editing, K.-S.L. and M.-H.L.; visualization, K.-S.L.; supervision, K.-S.L.; project administration, K.-S.L.; funding acquisition, K.-S.L. and M.-H.L. All authors have read and agreed to the published version of the manuscript. 
Funding: This research received no external funding.

Institutional Review Board Statement: Not applicable.

Informed Consent Statement: Not applicable.

Data Availability Statement: Data is not publicly available, though the data may be made available on request from the corresponding author.

Conflicts of Interest: The authors declare no conflict of interest.

\section{References}

1. Yin, R.K. Validity \& generalization in future case study evaluations. Evaluation 2013, 19, 321-332.

2. Heilig, L.; Voß, S. The intelligent supply chain: From vision to reality. Port Technol. 2018, 78, 80-82.

3. Gorecky, D.; Schmitt, M.; Loskyll, M.; Zuhlke, D. Human-machine-interaction in the industry 4.0 era. In Proceedings of the 12th IEEE International Conference on Industrial Informatics (INDIN), Porto Alegre, Brazil, 27-30 July 2014; pp. $289-294$.

4. Ivanov, D.; Dolgui, A.; Sokolov, B.; Werner, F.; Ivanova, M. A dynamic model and an algorithm for short-term supply chain scheduling in the smart factory industry 4.0. Int. J. Prod. Res. 2016, 54, 386-402. [CrossRef]

5. Agarwal, M.; Goel, S. Expert system and it's requirement engineering process. In Proceedings of the International Conference on Recent Advances and Innovations in Engineering (ICRAIE-2014), Jaipur, India, 9-11 May 2014; pp. 1-4.

6. Brettel, M.; Friederichsen, N.; Keller, M.; Rosenberg, M. How Virtualization, decentralization and network building change the manufacturing landscape: An Industry 4.0 Perspective. Int. J. Mech. Ind. Sci. Eng. 2014, 8, 37-44.

7. Lee, J.; Bagheri, B.; Kao, H.A. A cyber-physical systems architecture for industry 4.0-Based manufacturing systems. Manuf. Lett. 2015, 3, 18-23. [CrossRef]

8. Hong, J.; Zhang, Y.; Ding, M. Sustainable supply chain management practices, supply chain dynamic capabilities, and enterprise performance. J. Clean. Prod. 2018, 172, 3508-3519. [CrossRef]

9. Enrique, D.; Juan, S. Partnership building as an approach to addressing corporate social responsibility. Dev. South. Afr. 2018, 5, 281-287.

10. Wang, C.-H. How organizational green culture influences green performance and competitive advantage. J. Manuf. Technol. Manag. 2019, 30, 666-683. [CrossRef]

11. Wang, Y.; Jeong, H.H.; Beynon-Davies, P. Understanding blockchain technology for future supply chains: A systematic literature review and research agenda. Supply Chain Manag. Int. J. 2019, 24, 62-84. [CrossRef]

12. Ardito, L.; Petruzzelli, A.M.; Panniello, U.; Garavelli, A.C. Towards industry 4.0. Bus. Process. Manag. J. 2019, 25, 323-346. [CrossRef]

13. Chase, C.W., Jr.; CPF. The digital revolution is changing the supply chain landscape. J. Bus. Forecast. 2016, 35, 20-22.

14. Gargalo, C.; Pons, E.P.; Barbosa-Povoa, A.; Carvalho, A. A Lean Approach to Developing Sustainable Supply Chains. Sustainability 2021, 13, 3714. [CrossRef]

15. Dong, H.; Dong, S. Study and Application of Supplier Performance Evaluation System Based on the Triple-A Supply Chain. Appl. Mech. Mater. 2013, 397-400, 2636-2640. [CrossRef]

16. Alkayal, E.; Bogurcu, M.; Ulutas, F.; Demirer, G. Adaptation to Climate Change in Industry: Improving Resource Efficiency through Sustainable Production Applications. Water Environ. Res. 2015, 87, 14-25. [CrossRef] [PubMed]

17. Hsu, C.-H.; Chang, A.-Y.; Zhang, T.-Y.; Lin, W.-D.; Liu, W.-L. Deploying Resilience Enablers to Mitigate Risks in Sustainable Fashion Supply Chains. Sustainability 2021, 13, 2943. [CrossRef]

18. Kang, S.; Moon, T. Influence of system integration and supply chain integration on supply chain performance: A virtual integration theory perspective. Int. Inf. Inst. (Tokyo) Inf. 2017, 20, 4211-4218.

19. Hofmann, E.; Osterwalder, F. Third-party logistics providers in the digital age: Towards a new competitive arena? Logistics 2017, 1,9. [CrossRef]

20. Chai, Y.; Li, Q.; Zhang, J.; Xu, J. Research and empirical analysis of supply chain integration dynamic model and control in supply side. Rev. Cercet. Interv. Soc. 2018, 63, 131-148.

21. Zheng, Q.; Wang, M.; Yang, F. Optimal Channel Strategy for a Fresh Produce E-Commerce Supply Chain. Sustainability 2021, 13, 6057. [CrossRef]

22. Ma Gloria, V.T. Supply chain integration and performance: Revisiting the philippine experience. Philipp. Manag. Rev. 2017, 24, 63-82.

23. Florian, B.; Abubaker, H. Procurement 4.0: Factors influencing the digitisation of procurement and supply chains. Bus. Process. Manag. J. 2018, 24, 965-984.

24. Jahani, N.; Sepehri, A.; Vandchali, H.R.; Tirkolaee, E.B. Application of Industry 4.0 in the Procurement Processes of Supply Chains: A Systematic Literature Review. Sustainability 2021, 13, 7520. [CrossRef]

25. Wu, Y.; Wang, S. Sustainable Market Entry Strategy under a Supply Chain Environment. Sustainability 2021, 13, 3046. [CrossRef]

26. Rajaguru, R.; Matanda, M.J. Role of compatibility and supply chain process integration in facilitating supply chain capabilities and organizational performance. Supply Chain Manag. Int. J. 2019, 24, 301-316. [CrossRef]

27. Lasi, H.; Fettke, P.; Kemper, H.-G.; Feld, T.; Hoffmann, M. Industry 4.0. Bus. Inf. Syst. Eng. 2014, 6, 239-242. [CrossRef] 
28. Wang, S.; Wan, J.; Li, D.; Zhang, C. Implementing smart factory of industrie 4.0: An outlook. Int. J. Distrib. Sens. Netw. 2016, 12, 3159805. [CrossRef]

29. Yin, S.; Kaynak, O. Big data for modern industry: Challenges and trends [point of view]. Proc. IEEE 2015, 103, 143-146. [CrossRef]

30. Hu, J.; Liu, Y.-L.; Yuen, T.W.; Lim, M.K.; Hu, J. Do green practices really attract customers? The sharing economy from the sustainable supply chain management perspective. Resour. Conserv. Recycl. 2019, 149, 177-187. [CrossRef]

31. Fornell, C.; Larcker, D.F. Evaluating structural equation models with unobservable variables and measurement error. J. Mark. Res. 2018, 28, 39-50.

32. Sharma, V.; Poulose, J.; Mohanta, S.; Antony, L.E. Influence of the dimensions of CSR activities on consumer purchase intention. Innov. Mark. 2018, 14, 23-32. [CrossRef]

33. Bandar, K.A. Impact of service quality on customer trust, purchase intention and store loyalty, with mediating role of customers' satisfaction on customer trust and purchase intention: Study of grocery shopping. Br. J. Mark. Stud. BJMS 2019, 7, 40-61.

34. Mensah, I.; Mensah, R. Effects of service quality and customer satisfaction on repurchase intention in restaurants on University of Cape Coast campus. J. Tour. Herit. Serv. Mark. 2018, 4, 27-36.

35. Rivera, J.J.; Bigne, E.; Curras-Perez, R. Effects of Corporate Social Responsibility on consumer brand loyalty. Rev. Bus. Manag. 2019, 21, 395-415. [CrossRef]

36. Liu, J.S.; Lu, L.Y.; Ho, M.H.C. A few notes on main path analysis. Scientometrics 2019, 119, 379-391. [CrossRef]

37. Githiri MKhayiya, R.; Mutisya, M. Influence of service quality towards customer satisfaction and return intention: A Study at star-rated restaurants. J. Prod. Brand Manag. 2018, 21, 341-349.

38. Akhigbe, J.O.; Olokoyo, F.O. Corporate Social Responsibility \& Brand Loyalty in the Nigerian Telecommunication Industry. IOP Cinference Series: Earth Environment Science; IOP Publishing: Bristol, UK, 2019; Volume 331, p. 012063.

39. Tseng, M.L.; Islam, M.S.; Karia, N.; Fauzi, F.A.; Afrin, S. A literature review on green supply chain management: Trends and future challenges. Resour. Conserv. Recycl. 2019, 141, 145-162. [CrossRef]

40. Choi, S.Y.; Lee, H.; Yoo, Y. The impact of information technology and transactive memory systems on knowledge sharing, application, and team performance: A field study. MIS Q. 2010, 34, 855-870. [CrossRef]

41. Ivanov, S.H.; Webster, C.; Berezina, K. Adoption of robots and service automation by tourism and hospitality companies. Rev. Tur. Desenvolv. 2017, 27/28, 1501-1517.

42. Patel, V.L.; Shortliffe, E.H.; Stefanelli, M.; Szolovits, P.; Berthold, M.R.; Bellazzi, R.; Abu-Hanna, A. The coming of age of artificial intelligence in medicine. Artif. Intell. Med. 2009, 46, 5-17. [CrossRef] [PubMed]

43. Delbari, S.A.; Ng, S.I.; Aziz, Y.A.; Ho, J.A. An investigation of key competitiveness indicators and drivers of full-service airlines using Delphi and AHP techniques. J. Air Transp. Manag. 2016, 52, 23-34. [CrossRef]

44. Mishra, M.; Chatterjee, S. Application of Analytical Hierarchy Process (AHP) algorithm to income insecurity susceptibility mapping-A study in the district of Purulia, India. Socio-Econ. Plan. Sci. 2018, 62, 56-74. [CrossRef]

45. Charnes, A.; Cooper, W.W.; Rhodes, E. Measuring the efficiency of decision making units. Eur. J. Oper. Res. 1978, 2, 429-444. [CrossRef]

46. Banker, R.D.; Charnes, A.; Cooper, W.W. Some Models for Estimating Technical and Scale Inefficiencies in Data Envelopment Analysis. Manag. Sci. 1984, 30, 1078-1092. [CrossRef]

47. Gligor, D.M. The role of demand management in achieving supply chain agility. Supply Chain Manag. Int. J. 2014, 19, 577-591. [CrossRef]

48. Gligor, D.M.; Holcomb, M.C. Understanding the role of logistics capabilities in achieving supply chain agility: A systematic literature review. Supply Chain Manag. Int. J. 2012, 17, 438-453. [CrossRef]

49. Sanders, N.; Swink, M. Digital Supply Chain Transformation: Visualizing the Possibilities. Supply Chain. Manag. Rev. 2019, 23, 30-41.

50. Scholz, J.; De Meyer, A.; Marques, A.S.; Pinho, T.M.; Boaventura-Cunha, J.; Jos, V.O.; Rosset, C.; Künzi, J.; Kaarle, J.; Nummila, K. Digital technologies for forest supply chain optimization: Existing solutions and future trends. Environ. Manag. 2018, 62, 1108-1133. [CrossRef] [PubMed] 